\title{
Article \\ Coffee Grounds-Derived CNPs for Efficient Cr(VI) Water Remediation
}

\author{
Simona Bettini ${ }^{1,2, *} \mathbb{C}$, Michela Ottolini $^{3}$, Rosanna Pagano ${ }^{1,2}$, Sudipto Pal ${ }^{3}{ }^{\circledR}$, Antonio Licciulli $^{3}$, \\ Ludovico Valli ${ }^{1,2}$ (1) and Gabriele Giancane ${ }^{2,4, * \mathbb{D}}$
}

1 Department of Biological and Environmental Sciences and Technologies, DISTEBA, University of Salento, Via per Arnesano, I-73100 Lecce, Italy; rosanna.pagano@unisalento.it (R.P.); ludovico.valli@unisalento.it (L.V.)

2 Consorzio Interuniversitario Nazionale per la Scienza e Tecnologia dei Materiali, INSTM, Via G. Giusti, 9, I-50121 Firenze, Italy

3 Department of Engineering for Innovation, University of Salento, Via per Monteroni, I-73100 Lecce, Italy; michela.ottolini@unisalento.it (M.O.); sudipto.pal@unisalento.it (S.P.); antonio.licciulli@unisalento.it (A.L.)

4 Department of Cultural Heritage, University of Salento, Via D. Birago, 48, I-73100 Lecce, Italy

* Correspondence: simona.bettini@unisalento.it (S.B.); gabriele.giancane@unisalento.it (G.G.); Tel.: +39-083-229-9445 (S.B.); +39-083-229-9442 (G.G.)

Citation: Bettini, S.; Ottolini, M.;

Pagano, R.; Pal, S.; Licciulli, A.; Valli,

L.; Giancane, G. Coffee

Grounds-Derived CNPs for Efficient $\mathrm{Cr}(\mathrm{VI})$ Water Remediation.

Nanomaterials 2021, 11, 1064. https://

doi.org/10.3390/nano11051064

Academic Editor: Constantine

D. Stalikas

Received: 23 March 2021

Accepted: 17 April 2021

Published: 21 April 2021

Publisher's Note: MDPI stays neutral with regard to jurisdictional claims in published maps and institutional affiliations.

\begin{abstract}
Carbon nanomaterials are a group of materials characterized by $\mathrm{sp}^{2} / \mathrm{sp}^{3}$ carbon backbone which, combined with surface atoms and/or chemical groups, ensures peculiar physical chemical features for a wide range of applications. Among these materials, carbon dots and carbon nanoparticles belong to carbon nanomaterials with a few nanometer dimensions. In this work, carbon nanoparticles were produced from spent coffee grounds as sustainable carbon source through a simple, cheap and eco-friendly procedure according to an oxidation process (at controlled temperature) driven by hydrogen peroxide. Atomic Force Microscope (AFM) and fluorescence, UV-Vis absorption, FT-IR and Raman spectroscopy were used to assess the formation of carbon nanomaterials of about $10 \mathrm{~nm}$ with the typical emission and absorption properties of carbon dots and peculiar surface features. In fact, the presence of heteroatoms, i.e., phosphorus, and the carbonyl/carboxyl surface groups on carbon nanoparticles, was proposed to confer peculiar properties allowing the fast $\mathrm{Mn}$ (VII) reduction to $\mathrm{Mn}(\mathrm{II})$ at neutral $\mathrm{pH}$ and the $\mathrm{Cr}(\mathrm{VI})$ reduction to $\mathrm{Cr}(\mathrm{III})$ in weak acid aqueous media.
\end{abstract}

Keywords: carbon dots; carbon nanoparticles; $\mathrm{Cr}(\mathrm{VI})$ remediation; hexavalent chromium; spent coffee grounds

\section{Introduction}

The increasing and unusual episodes concerning emerging pollutant effects on water purity and availability have prompted a remarkable enhancement in investigations aiming at facing and limiting these novel challenges. The remediation to this contemporary society problem has involved several approaches such as adsorption onto disparate kinds of adsorbents [1], filtration [2], flotation [3], ion exchange [4], microbiology methods [5], photo-induced redox reactions [6], precipitation [7], reverse osmosis [8], photocatalysis [9] and so on.

Among contaminants, harmful heavy metals tend to accumulate and show pronounced permeation properties. They are usually derived from anthropogenic activities, mainly in industrial and agricultural areas. Taking into account the extensive applications of transition metals in manufacturing processes, their consequent pollution problems demand pressing and priority solutions. In this research, we have undertaken investigations with the goal of demonstrating the potentialities of our green-synthesized carbon dots in the remediation of criticisms induced by transition metals such as Chromium and Manganese in aqueous environments.

In the large family of carbon dots (CDs), it is possible to gather together all the materials mainly composed of carbon atoms and with dimensions of a few nanometers [10]. 
From a chemical point of view, CDs consist of $\mathrm{sp}^{2} / \mathrm{sp}^{3}$ carbons and oxygen and/or nitrogen containing pendant groups. Several species belong to the CDs family: graphene quantum dots [11], carbon nanotubes [12,13], fullerenes [14], polymer dots [15] and carbon nanodots (CNDs) $[16,17]$. In particular, CNDs can be further divided into carbon quantum dots (CQDs) and carbon nanoparticles (CNPs) [18]. Both CQDs and CNPs are spherically shaped though CQDs have a crystal lattice; in contrast, CNPs do not show any crystal lattice [19].

CNDs show very interesting photoluminescence features [19] that propose such materials for several applications. For example, they can be used as a bioimaging and theranostic agent [20], as a hole transporter layer [21] or as a photoactive material in solar cell devices [22]; they can also promote the formation of singlet oxygen for anticancer applications if opportunely doped [23]. Also, they can be used as photocatalysts [24-26], in sensing and biosensing applications $[27,28]$ and in environmental pollution control [29]. CDs can be obtained by means of a top-down approach or bottom-up method [30,31]. In the first case, carbon atoms are cut from graphene oxide, nanotubes or carbon fibers. In the bottom-up method, carbon-based materials [32], such as hexabenzocoronene [33] arginine [34] and urea [35] are used as the carbon source.

In the present manuscript, the bottom-up approach has been used to obtain CNPs starting from coffee grounds as a carbon source according to a relatively simple and rapid pyrolysis-based procedure. The obtained nanostructures were used to efficiently convert the well-known genotoxic cancerogenic agent $\mathrm{Cr}(\mathrm{VI})$ ion into the more environmentally friendly $\mathrm{Cr}(\mathrm{III})$. Hexavalent chromium can be absorbed by the lung and gastrointestinal tract [36] and when internalized in the cells, it can react producing reactive intermediates capable to attack DNA, proteins and lipidic membranes, thereby affecting the cellular vitality and integrity. It is worth underlining and stressing that water remediation from toxic ions and compounds has developed in recent years as a hot and particularly emotive and controversial topic [37-40]. Most of the remediation methods regarding $\mathrm{Cr}(\mathrm{VI})$ reported in the literature are based on reduction to $\mathrm{Cr}$ (III) by oxidation-reduction reactions in the presence of elemental $\mathrm{Fe}, \mathrm{Mn}(\mathrm{II}), \mathrm{S}^{2-}$, organic reducing compounds and a biological approach using bacterial strain [41-43]. Here, CNPs obtained from waste material have been used to quickly and effectively convert $\mathrm{Cr}(\mathrm{VI})$ into $\mathrm{Cr}(\mathrm{III})$, proposing the present approach in the frame of a circular economy and sustainable treatment and remediation of water sources. The environmentally and biologically compatible proposed carbon nanomaterials are suggested here as a proof-of-concept for the treatment of industrial and potable water for the remediation from $\mathrm{Cr}(\mathrm{VI})$ pollution.

\section{Materials and Methods}

\subsection{Materials}

Spent coffee grounds were used as the carbon precursor. Acetic acid (glacial, ACS reagent, $\geq 99.7 \%$,), sodium chromate tetrahydrate $(99 \%)$, potassium permanganate (ACS reagent, $\geq 99.0 \%$ ) and manganese (II) sulfate monohydrate (ACS reagent, $\geq 98 \%$ ) were purchased from Sigma-Aldrich (St. Louis, Missouri, US) and used as received without any further purification. All the experiments were carried out using ultrapure MilliQ grade water.

\subsection{Synthesis Methods of CNPs}

The approach adopted in this work consists of two steps: first, coffee ground powders were carbonized at $600{ }^{\circ} \mathrm{C}$ for one hour; in the second step, $0.1 \mathrm{~g}$ of carbonized coffee grounds were dispersed in $10 \mathrm{~mL}$ of ultrapure MilliQ grade water and mixed with $150 \mu \mathrm{L}$ of $\mathrm{H}_{2} \mathrm{O}_{2}(30 \%)$ under sonication for $20 \mathrm{~min}$, allowing oxidation events to start. Then, the reaction mixture was heated at $150{ }^{\circ} \mathrm{C}$ for $90 \mathrm{~min}$. Then, it was left to cool at room temperature and the volume was again adjusted to $10 \mathrm{~mL}$ by adding ultrapure MilliQ grade water. The dark brown suspension obtained was centrifuged (8000 rpm for $20 \mathrm{~min}$ ) 
and filtered ( $0.45 \mu \mathrm{m}$ hydrophilic filter), yielding a yellowish colloidal solution typical of CDs with a concentration of about $0.5 \mathrm{~g} \mathrm{~L}^{-1}$.

\subsection{CNPs Characterization}

Fluorescence spectra were acquired by a fluorescence spectrophotometer (Horiba Jobin Yvon Fluorolog) by changing excitation wavelength in the range $300-420 \mathrm{~nm}$ for the down conversion experiments and between 700 and $800 \mathrm{~nm}$ for the up-conversion measurements. UV-Visible measurements were carried out by using a Perkin Elmer Lambda $650 \mathrm{spec}-$ trophotometer. The Fourier Transform Infrared (FT-IR) spectroscopic characterization was performed by using a PerkinElmer Spectrum One IR spectrometer in Attenuated Total Reflectance (ATR) mode [44]. Each spectrum is the average of 32 scans $\left(4 \mathrm{~cm}^{-1}\right.$ resolution) in the range from 800 to $4000 \mathrm{~cm}^{-1}$. Lapped $\mathrm{Si} / \mathrm{SiO}_{2}$ substrate was used to deposit by drop casting the samples for the morphological analysis by means of an Atomic Force Morphology (AFM) instrument (SmartSPM 1000 AIST-NT HORIBA). Micro Raman Xplora (Horiba) with a laser at $532 \mathrm{~nm}$ was used for acquiring Raman spectra.

$X$-ray Diffraction (XRD) measurements were carried out on the as synthesized sample using Rigaku Ultima diffractometer $(\mathrm{Cu} K \alpha$ radiation, $\lambda=1.5406 \AA)$ operating at $40 \mathrm{kV} / 20 \mathrm{~mA}$ with the step size of $0.02^{\circ}$. For this purpose, a multilayer film was deposited on the polished silicon wafer by the drop casting method from the aqueous suspension of CNPs, followed by drying. Elemental analysis on spent coffee grounds and CNPs was carried out by the X-ray Fluorescence spectroscopy (XRF) technique by using a M4 TORNADO Micro-XRF spectrometer (Bruker Nano, Berlin, Germany) operating at $50 \mathrm{kV} / 600 \mu \mathrm{A}(30 \mathrm{~W})$ equipped with an X-Flash solid state silicon drift detector. The grounded coffee powders were directly measured by making a pellet when CNPs were drop casted on Silicon wafer to form a multilayer film.

$\zeta$-Potential measurements of as synthetized CNPs and after the remediation experiments were performed using a Malvern Panalytical Nano ZS Zetasizer instrument (Malvern Panalytical Limited, Malvern, UK).

\section{Results}

The UV-Visible spectrum of CNPs dissolved in ultrapure water solution was recorded and it is reported in Figure 1a. The typical spectral profile of CDs exhibits a weak absorption band located at $290 \mathrm{~nm}$, imputable at $\mathrm{n}-\pi^{*}$ transition of $\mathrm{C}=\mathrm{O}$ and $\mathrm{N}=\mathrm{O}$ groups $[45,46]$.
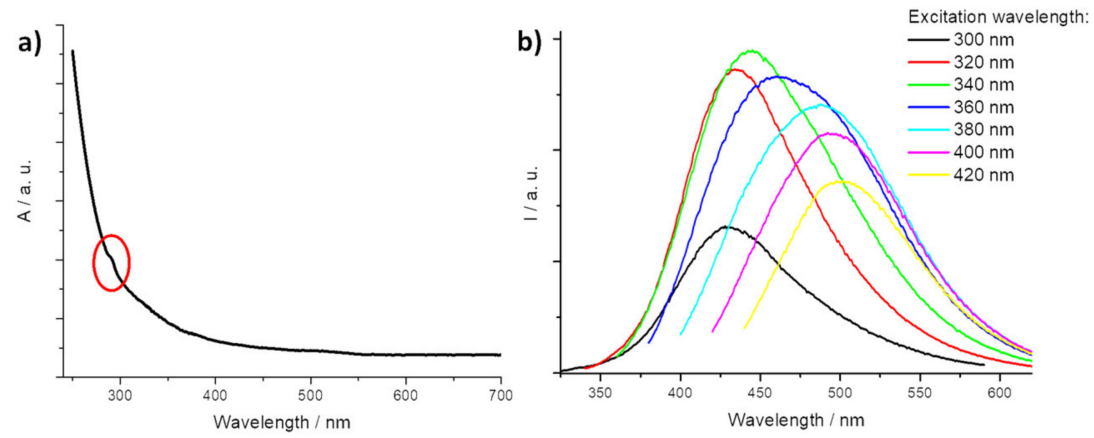

Figure 1. (a) UV-Visible spectrum of CNPs. In the red oval, the transition band $n-\pi^{*}$ is highlighted. (b) Fluorescence emission obtained irradiating the CNPs solution with different excitation wavelengths.

Emission spectra, obtained by excitation at different wavelengths, were recorded (Figure 1b). The characteristic emission features of CNPs were observed when the excitation wavelength was changed from $300 \mathrm{~nm}$ to $420 \mathrm{~nm}$ with a step of $20 \mathrm{~nm}$. The maximum intensity of photoluminescence emission for $0.05 \mathrm{~g} \mathrm{~L}^{-1} \mathrm{CNPs}$ aqueous solution was located at about $445 \mathrm{~nm}$ upon $340 \mathrm{~nm}$ excitation with a monotonic intensity increasing from $320 \mathrm{~nm}$ to a $340 \mathrm{~nm}$ excitation wavelength [47]. The photoluminescence phenomenon of CDs is still debated and is usually attributed to both the surface states (depending on hybridization 
of the carbon backbone and chemical groups on the dots surface) and to the conjugated $\pi$-domains, which are determined by the carbon core [19]. The synthesized CNPs exhibited good up-conversion fluorescent properties with the emission peak position depending on the excitation wavelength, with a maximum located at about $500 \mathrm{~nm}$ for an excitation wavelength at $800 \mathrm{~nm}$ (Figure S1).

Raman spectrum obtained using a $532 \mathrm{~nm}$ excitation laser is reported in Figure $2 \mathrm{a}$ and shows the typical presence of D and $G$ bands located at 1360 and $1590 \mathrm{~cm}^{-1}$, respectively. The D-peak in the Raman spectrum is usually attributed to the contribution from defects, surface functionalization groups and edge effect. On the other side, the G-band corresponds to the graphitization associated with the CNPs [48]. The intensity ratio between the Gpeak and D-peak is about 1.2 and it suggests that the as-synthetized CNPs are partially composed of a crystalline graphitic structure. The formation of carbon dots was confirmed by X-ray diffraction performed at low $\theta$ (Figure $2 \mathrm{~b}$ ) that clearly shows a broad diffraction peak at about $20^{\circ}$ imputable to the amorphous carbonic structure [49]. No sharp peak was observed in the XRD patterns, confirming the amorphous character of the synthetized carbon nanostructures [50].

a)

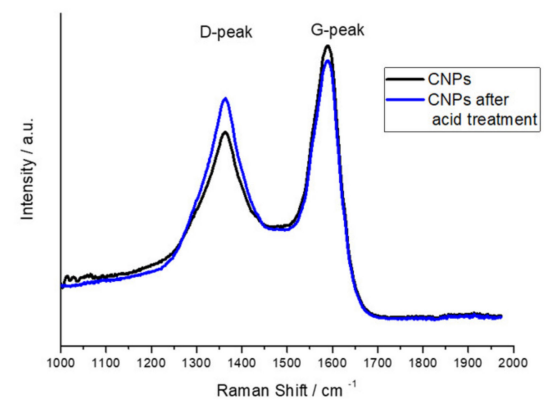

b)

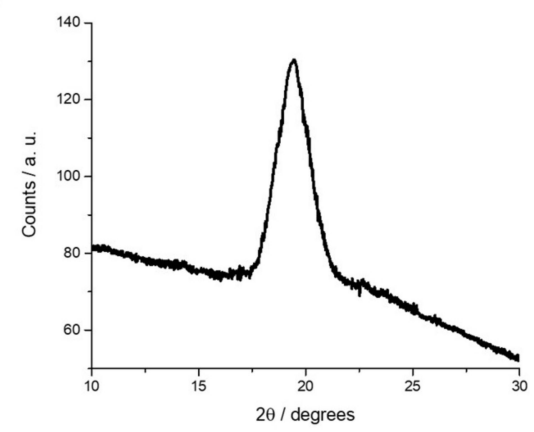

Figure 2. (a) Raman spectra of as-synthetized CNPs and after $1 \mathrm{~h}$ acid treatment at $\mathrm{pH} 4.5$ (b) XRD spectrum of as synthetized CNPs.

The CNPs composition was investigated by means of X-ray fluorescence and FT-IR spectroscopy. XRF highlights the presence of phosphorous both in the starting material (the coffee grounds) and in the CNPs. After the synthesis procedure, the presence of contaminant elements such as calcium, sulfur and iron is strongly reduced (Table 1); in contrast, $\mathrm{P}$ and $\mathrm{Mg}$ atoms are still present in the formed CNPs (Table 1).

FT-IR spectroscopy was performed to characterize the overall synthesis procedure starting from the raw material, coffee grounds, up to the final product, CNPs. The black line in Figure 3 corresponds to IR features of coffee grounds and is in perfect agreement with the literature [36]. The spectrum is characterized by the presence of the typical lignocellulosic materials vibrations in the region comprised between 3600 and $3200 \mathrm{~cm}^{-1}$ due to the $\mathrm{O}-\mathrm{H}$ stretching mode and between 1100 and $950 \mathrm{~cm}^{-1}$ due to $\mathrm{C}-\mathrm{O}$ stretching modes of cellulose, hemicellulose and lignin [51,52]. The C-H stretching mode frequency range (3015-2850 $\mathrm{cm}^{-1}$ ) evidences several and intense contributions due to $\mathrm{CH}$ vibrations of alkyl chains of fats and of xanthine derivatives (i.e., caffein and chlorogenic acid) [53,54]. Further, diverse signals arising from caffeine or in general xanthine content are evident and ascribable to $\mathrm{C}=\mathrm{O}, \mathrm{C}-\mathrm{N}$ and N-H groups: at $3130 \mathrm{~cm}^{-1}$ the N-H stretching; at $1745 \mathrm{~cm}^{-1}$ the imidazole $\mathrm{C}=\mathrm{O}$; at $1660 \mathrm{~cm}^{-1}$ the carboxyl asymmetric stretching mode; at 1260 and $1155 \mathrm{~cm}^{-1} \mathrm{C}-\mathrm{N}$ stretching of xanthine side chain and imidazole, respectively; between 950 and $800 \mathrm{~cm}^{-1} \mathrm{~N}-\mathrm{C}-\mathrm{H}$ deformations of xanthine side chains [55]. 
Table 1. Elemental composition of the coffee grounds and CNPs quantified from the XRF measurement.

\begin{tabular}{ccccc}
\hline \multirow{2}{*}{ Elements } & \multicolumn{2}{c}{ Coffee Grounds } & \multicolumn{2}{c}{ CNPs * } \\
\cline { 2 - 5 } & Weight \% & Atomic \% & Weight \% & Atomic \% \\
\hline $\mathrm{Ca}$ & 47.10 & 44.31 & 10.40 & 7.73 \\
\hline $\mathrm{S}$ & 10.88 & 12.79 & 0.21 & 0.20 \\
\hline $\mathrm{Mg}$ & 8.53 & 13.23 & 20.67 & 25.35 \\
\hline $\mathrm{Fe}$ & 8.13 & 5.49 & 0.53 & 0.28 \\
\hline $\mathrm{K}$ & 8.02 & 7.73 & 7.00 & 5.33 \\
\hline $\mathrm{P}$ & 4.48 & 5.45 & 42.60 & 41.00 \\
\hline $\mathrm{Al}$ & 3.86 & 5.39 & 17.86 & 19.73 \\
\hline $\mathrm{Zn}$ & 3.85 & 2.22 & 0.40 & 0.18 \\
\hline $\mathrm{Mn}$ & 2.26 & 1.55 & 0.13 & 0.07 \\
\hline $\mathrm{Cu}$ & 2.19 & 1.3 & 0.03 & 0.01 \\
\hline $\mathrm{Ni}$ & 0.52 & 0.33 & 0.12 & 0.06 \\
\hline $\mathrm{Si}$ & 0.10 & 0.13 & - & 0.04 \\
\hline $\mathrm{Ti}$ & 0.09 & 0.07 & 0.06 &
\end{tabular}

* Elemental contribution of silicon from the Si substrate was not considered.

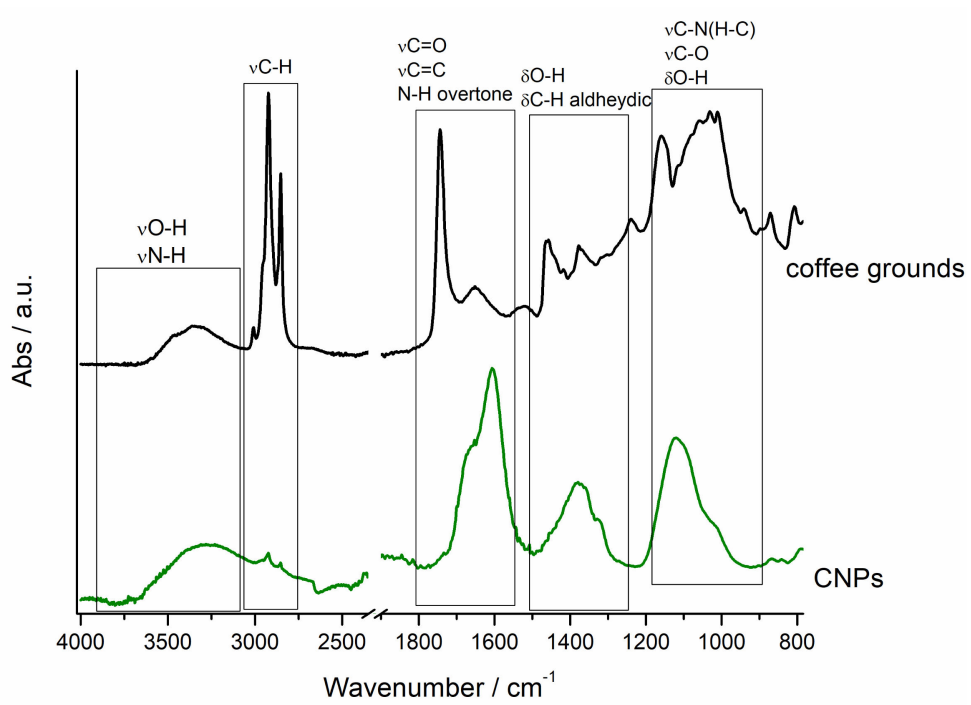

Figure 3. FT-IR spectra of coffee grounds and CNPs.

The carried-out reaction entails an oxidation process allowing precursor fragmentation and the next nucleation and growth of CNPs, and accordingly remarkable changes of FT-IR features of the formed CNPs (green line Figure 3). In fact, at between 3630 and $3020 \mathrm{~cm}^{-1}$ a broad band arising from $\mathrm{OH}$ and $\mathrm{NH}$ stretching modes is exhibited, between 3000 and $2800 \mathrm{~cm}^{-1} \mathrm{C}-\mathrm{H}$ stretching arising from both graphitic and aliphatic carbon is evident, between 1670 and $1590 \mathrm{~cm}^{-1}$ range contributions that can be assigned to $\mathrm{C}=\mathrm{O}$ (partially carboxylic and partially aldehydic) stretching vibration and a combination of $\mathrm{C}=\mathrm{C}$ stretching and $\mathrm{NH}$ overtones are apparent [56], between 1380 and $1310 \mathrm{~cm}^{-1} \mathrm{O}-\mathrm{H}$ bending and aldehydic $\mathrm{C}-\mathrm{H}$ bending are observable and finally in the range $1150-950 \mathrm{~cm}^{-1}$ C-NH-C stretching [57] and carboxylic moieties C-O stretching modes are detectable.

The morphology of the synthetized CNPs was studied by means of atomic force microscopy and it was compared with the carbon nanoparticles images after acidification (Figure $4 a, b)$. The AFM image of the as-synthetized CNPs shows spherical structures of about $10 \mathrm{~nm}$ (see the inset image in the Figure 4c) according to the literature data about 
carbon dots that were obtained with similar synthetic procedures [58]. The morphology of the nanostructures did not appear to be influenced by acid treatment (Figure $4 \mathrm{~b}$ ), as they still showed spherical structures of about $10 \mathrm{~nm}$. In contrast, a $\zeta$-potential investigation performed on the as-synthetized CNPs showed a surface charge of about $-12 \mathrm{mV}$ that increases up to $-24.7 \mathrm{mV}$ after the treatment of the carbon dots with acetic acid for $1 \mathrm{~h}$ at $\mathrm{pH}$ 4.5. The interaction with chromium ions, $\mathrm{Cr}(\mathrm{VI})$ did not influence the surface charge or the exposure to permanganate (Figure S2).

a)

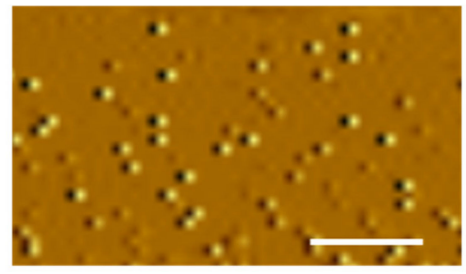

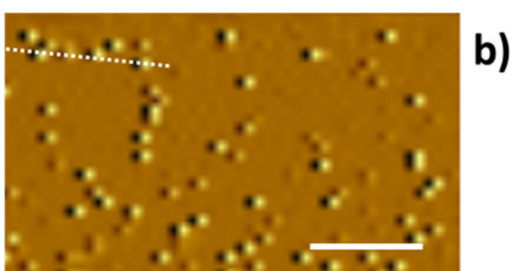

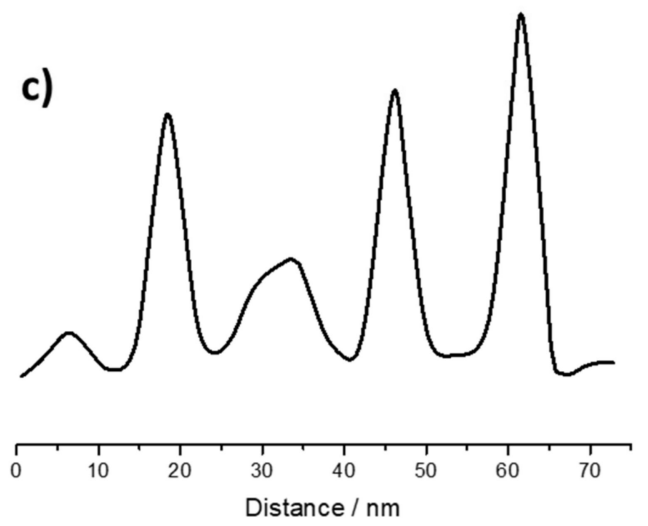

Figure 4. AFM images of the CNPs (a) as synthetized and (b) after acid treatment ( $\mathrm{pH} 4.5$ for $1 \mathrm{~h}$ ). The bar in the figures is $50 \mathrm{~nm}$ wide. Image (c) reports the carbon dots z-profiles related to image CNPs in image (b) crossed by the white line.

The effect of the acid treatment on the Raman signals is evident when comparing the G/D band ratio of the bare CNPs and the acid treatment performed on the carbon nanostructures (Figure 2). The intensity ratio between G-peak and D-peak changed from 1.2 in the case of the as-synthetized CNPs to 1.07 after $1 \mathrm{~h}$ acid treatment, suggesting that the number of defect sites on the surface of CNPs increases under the acid attack. On the other side, the intensity ratio between G-peak and D-peak is not influenced by the presence of $\mathrm{Cr}(\mathrm{VI})$ in the solution (Figure S3a). It is very interesting to observe that the effect of permanganate ion is very similar, and even stronger, in comparison with that one observed in the case of the acid treatment. When the carbon dots are exposed to potassium permanganate, the G-peak/D-peak intensity ratio decreases down to 1.04 (Figure S3b).

FT-IR investigations on CNPs treated at $\mathrm{pH} 4.5$ for $1 \mathrm{~h}, \mathrm{CNPs}$ treated with $\mathrm{Cr}(\mathrm{VI})$ at both $\mathrm{pH} 6.6$ and $\mathrm{pH} 4.5$ and of CNPs treated with $\mathrm{Mn}(\mathrm{VII})$ at $\mathrm{pH} 6.6$ are all reported in Figure $\mathrm{S} 4$. The experimental results suggest that the signals arising from $\mathrm{C}=\mathrm{O}$ (with a shift towards higher wavenumbers at about $1700 \mathrm{~cm}^{-1}$ ), C-O, O-H and $\mathrm{C}-\mathrm{H}$ aldehydic vibrations are influenced at $\mathrm{pH} 4.5$, suggesting the formation of a larger amount of carboxylic moieties: two peaks at $1418 \mathrm{~cm}^{-1}$ and $942 \mathrm{~cm}^{-1}$ arising from in plane and out of plane modes, respectively, of carboxylic $\mathrm{OH}$ are evident (red line Figure S4). This behavior is still visible in the presence of $\mathrm{Cr}(\mathrm{VI})$ at $\mathrm{pH} 4.5$, even if these two signals become substantially less pronounced. The FT-IR features of CNPs, instead, in the presence of the two oxidizing ions at $\mathrm{pH}$ 6.6, remain almost unchanged. These observations are in very good agreement with the obtained results from $\zeta$-potential. Fluorescence features of CNPs are strongly influenced by the solution $\mathrm{pH}$. The photoluminescence of CNPs at natural $\mathrm{pH}(\mathrm{pH}=6.6)$ appears 
quenched by the presence of sodium chromate $\left(10^{-4} \mathrm{M}\right)$. It is interesting to observe that when the sodium chromate is dissolved in CNPs water solution at $\mathrm{pH} 4.5$, the fluorescence intensity is reduced of the same amount observed for the CNPs dissolved in water at $\mathrm{pH} 4.5$ (Figure S5). In fact, the fluorescence emission of CNPs is slightly influenced by the presence of $\mathrm{Cr}$ (III) ions in solution.

The effect of potassium permanganate perfectly fits the previously observed spectroscopic behaviors. In fact, $\mathrm{Mn}(\mathrm{VII})$ induces a remarkable quench of CNPs emission $\left(10^{-4} \mathrm{M}\right)$; in contrast, $\mathrm{Mn}(\mathrm{II})$, incapable of modifying the CNPs surface, induces only an almost negligible quench of CNP fluorescence (Figure S6).

More interesting than the spectroscopic changes induced by dichromate and permanganate ions on CNPs are the effects of CNPs on the dissolved $\mathrm{Cr}(\mathrm{VI})$ and $\mathrm{Mn}(\mathrm{VII})$. In fact, the presence of dichromate was monitored by means of UV-Visible spectroscopy considering the typical absorption band located at $350 \mathrm{~nm}$ (Figure 5a). When even a small amount of dots $\left(0.05 \mathrm{mg} \mathrm{mL}^{-1}\right)$ is added to the aqueous solution containing $\mathrm{Cr}(\mathrm{VI})$, the typically yellowish color of the solution immediately changes, for few seconds, in a green colored solution and then turns violet. As will be more deeply discussed in the next section, this suggests that the chromium ions change their oxidation state from +6 to +3 . Analogous behavior has been observed in the case of permanganate (Figure $5 b$ ).

a)

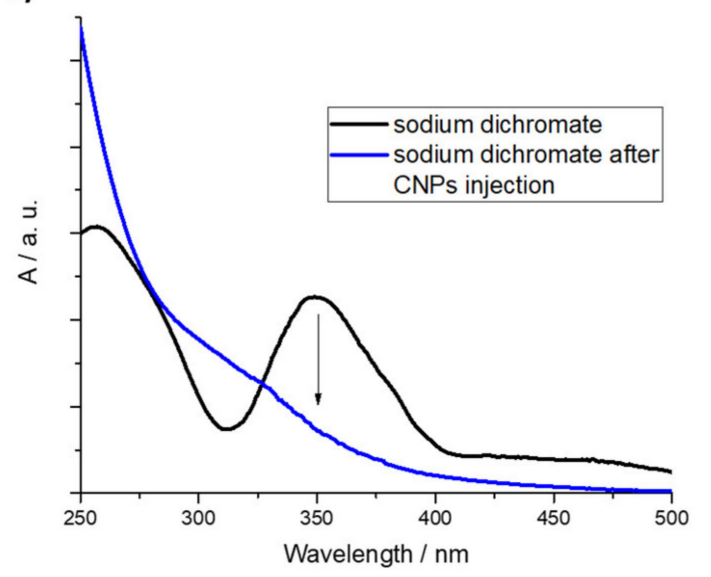

b)

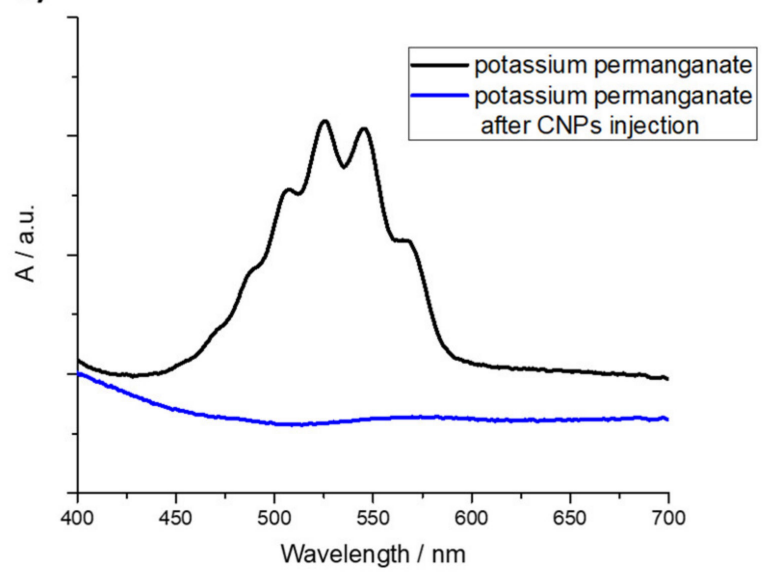

Figure 5. Spectroscopic evidence of the effect induced by CNPs on (a) dichromate and (b) permanganate solutions.

\section{Discussion}

CNPs have been prepared by using as starting materials spent coffee grounds as carbon source in the frame of circular economy and sustainable chemistry; furthermore, coffee grounds are reported to have potential toxic effects on human health and environment [53]. The developed synthetic approach requires two steps: first, the waste has to be powdered and carbonized; then, a $\mathrm{H}_{2} \mathrm{O}_{2}$ assisted pyrolysis is carried out in order to induce the strong oxidation processes allowing fragmentation, polymerization and nucleation of CNPs, as expected from similar reported procedures [59]. Moreover, the relatively mild conditions $\left(150{ }^{\circ} \mathrm{C}\right.$ and ambient pressure) permit us to preserve the presence of some natural doping agents that can influence the physical-chemical features of the formed CNPs [60].

Doped and undoped CNPs are usually used for their peculiar spectroscopic features. On the other side, the spectroscopic characteristics of a chemical compound are, in the widest sense, evidence of the electronical properties of the materials. The electronic cloud of the CNPs, similarly to other allotropic forms of carbon, such as fullerenes and carbon nanotubes, gives these compounds high chemical reactivity towards several species and proposes the CNPs for a plethora of applications [61]. In the present contribution, the 
synthetized carbon dots were successfully used for the treatment of pollutants dissolved in water.

\subsection{CNPs Spectroscopic Characterization}

The defect sites on CNPs surface act as active sites for promoting the oxidation process. [62]. Loss of crystalline structure on the carbon dots surface has been evidenced by the vibrational spectroscopy.

The surface chemical composition is reported to be fundamental for the further applications of CNPs; FT-IR is a powerful approach for achieving this kind of information. So, dehydrated coffee grounds and formed CNPs were both characterized by this technique. The results further indicate the complexity of the starting material, which is a mixture of different organic compounds, such as cellulose, lignin, hemicellulose, xanthine and fats (in a different percentage) [53], with an ash and mineral content as highlighted by XRF analysis.

Important information about the CNPs structure, size and dimension can be obtained from the CNPs Raman spectra. The position of the D peak is not related to the CNPs dimension, instead the G band position and the full-width half maximum (FWHM) of the $\mathrm{G}$ band are connected to the dot size [63]. In particular, for CNPs below $17 \mathrm{~nm}$, the $\mathrm{G}$ band shifts toward higher frequencies as the CNPs dimension increases and FWHM value decreases [64]. In the present case, the $G$ band position suggests that spherical nanostructures with dimensions comprised of $8 \mathrm{~nm}$ and $10 \mathrm{~nm}$ are formed and it is confirmed by the FWHM that results for the $G$ band are equal to $116 \mathrm{~cm}^{-1}$ [63].

The infrared vibrational approach allows understanding that the CNP surfaces, upon the carbonization and oxidation step, are essentially characterized by the vibrations of these chemical groups: $\mathrm{C}=\mathrm{C}, \mathrm{C}=\mathrm{O}, \mathrm{OH}, \mathrm{NH}$. In particular, aldehydic and alcoholic groups can be hypothesized to decorate CNP surfaces and contribute to a partial negative charge, as validated by $\zeta$-potential results that will be discussed hereafter.

The effect of acid treatment on the CNPs aims to induce the formation of further defect sites on the carbon surface, as confirmed by both FT-IR and Raman techniques. In particular, the D-band increases in comparison with the G-band when the dots are placed in acid environment. The acid attack reduces the order of the nanostructures, generating new defects and new active sites.

The formation of new defects on the dots surface was also confirmed by monitoring the ratio of $G$ band intensity $\left(\mathrm{I}_{\mathrm{G}}\right)$ to the $\mathrm{D}$ band intensity $\left(\mathrm{I}_{\mathrm{D}}\right)$. The $\mathrm{I}_{\mathrm{G}} / \mathrm{I}_{\mathrm{D}}$ decreases from 1.2 in the Raman spectrum of the as-synthetized CNPs to 1.07 after $1 \mathrm{~h}$ acid treatment at $\mathrm{pH}$ 4.5 (reached adding acetic acid drop-by-drop). The disorder D-band is related to defects in the graphite lattice (i.e., $\mathrm{sp}^{3}$ carbon atoms), and the G-band is related to $\mathrm{sp}^{2}$-hybridized carbon atom networks $[65,66]$. Furthermore, peak position and FWHM of $\mathrm{G}$ band are not influenced by the acid attack, suggesting (this is further confirmed by morphological characterization, Figure $4 \mathrm{~b}$ ) that the procedure does not influence the CNPs size but it is focused on the CNP surfaces.

$\zeta$-potential measurements furthermore support the surface modification induced by the acid attack. The surface charge variations from $-12 \mathrm{mV}$ to $-24.7 \mathrm{mV}$ confirm the rationale proposed by FT-IR analysis that underlines the presence of more carboxylic moieties on the surface after the acid treatment.

In contrast, the morphology of the CNPs seems to not be influenced by the acid action and the shape and dimension are preserved.

\subsection{Remediation Experiments}

For the treatment of chromium ions, different $\mathrm{pH}$ values have been used. In the first experiment, the sodium chromate $\left(10^{-4} \mathrm{M}\right)$ was completely converted in sodium dichromate at $\mathrm{pH} 2.5$ (Figure 5a). When the CNPs were added to the aqueous solution $\left(100 \mu \mathrm{L} 0.05 \mathrm{mg} \mathrm{mL}^{-1}\right.$ concentration), a rapid bleaching of the absorption band of 
$\mathrm{Na}_{2} \mathrm{Cr}_{2} \mathrm{O}_{7}$ at $350 \mathrm{~nm}$ is recorded. The yellow-orange colored solution quickly bleaches and a colorless solution is generated.

A very interesting result is obtained starting from a chromate/dichromate $\left(10^{-4} \mathrm{M}\right)$ solution at $\mathrm{pH}$ 4.5. In this condition, an equilibrium between chromate and dichromate is obtained. When the CNPs were added to the solution (100 $\mu \mathrm{L} 0.05 \mathrm{mg} \mathrm{mL}^{-1}$ concentration), the absorption band of chromate centered at $350 \mathrm{~nm}$ simultaneously decreases its intensity and shifts towards lower wavelengths (Figure 6). It is worth highlighting that an isosbestic point cannot be observed, thus testifying the participation of more than two species to the equilibrium. This can be explained as follows: at the initial stage, before the CNPs injection, a slightly acidic environment ( $\mathrm{pH} 4.5)$ promotes both the formation of new active sites on the CNPs carbon dots and the establishment of a new chromate/dichromate equilibrium. Presumably, the acid environment converts aldehydic into carboxylic moieties, as suggested by the FT-IR analysis (Figure S4), and this promotes the ion reduction. The sodium dichromate interacts with the carbon dots oxidation sites, reducing the chromium oxidation state from +6 to +3 . The FT-IR features of CNPs at $\mathrm{pH} 4.5$ upon the reduction of $\mathrm{Cr}(\mathrm{VI})$ indeed suggest the involvement of the carboxylic groups in this process, since the signals at $1418 \mathrm{~cm}^{-1}$ and $942 \mathrm{~cm}^{-1}$ arising from carboxylic $\mathrm{OH}$ appear to be quenched. This step reduces the dichromate concentration and, therefore the band at $350 \mathrm{~nm}$ is reduced. So, at least three species simultaneously exist in the solution and they are not in chemical equilibrium, as demonstrated by the blue spectrum in Figure 6 where both chromate and dichromate ions are reduced to $\mathrm{Cr}(\mathrm{III})$ by the mediation of CNPs. Fluorescence emission of CNPs at different $\mathrm{pH}$ values in the presence of sodium chromate confirms the proposed rationale (Figure S5). In fact, the acid environment strongly influences the CNPs fluorescence emission as a consequence of the creation of new defect sites on the carbon dots. When the sodium chromate is added to CNPs solution at $\mathrm{pH} 4.5$, no further quenching is observed since, as suggested by visible spectroscopy, the $\mathrm{Cr}(\mathrm{VI})$ is converted in $\mathrm{Cr}(\mathrm{III})$. Chromium(III), at the same concentration of the sodium chromate used to monitor the fluorescence alteration of the CNPs, only slightly influences their photoluminescence (Figure S5).

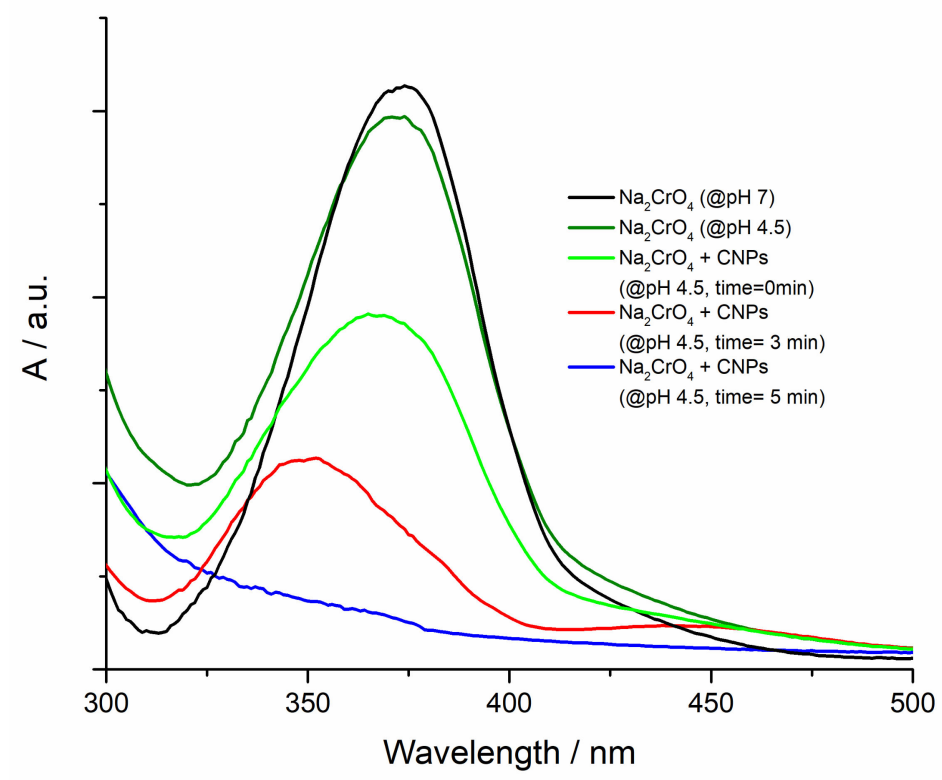

Figure 6. CNPs effect on Vis spectrum of $\mathrm{Cr}(\mathrm{VI})$ acid solution during the treatment and Vis spectrum of $\mathrm{Cr}(\mathrm{VI})$ at neutral $\mathrm{pH}$ in presence of CNPs (black line) for comparison.

The chemical reduction of permanganate can be achieved without any acid mediation. In fact, it is reported that $\mathrm{KMnO}_{4}$ promotes new defect sites on dot sites [62] and, according to the proposed rationale, the reduction of permanganate ion in the colorless $\mathrm{Mn}^{2+}$. This 
behavior does not induce chemical changes on CNPs surface, according to FT-IR and $\zeta$-potential investigations. The Mn oxidation state change was observed by means of UV-Visible spectroscopy (Figure 5b) by monitoring the rapid bleaching of the typical band of permanganate ion. As was reported in the case of $\mathrm{Cr}(\mathrm{VI})$, fluorescence measurements (Figure S6) confirms the rationale pointed out by means of UV-Visible spectroscopy. Mn(VII) is able to promote the formation of new defect sites on the CNPs, activating the carbon allotropes for the permanganate reduction, and this phenomenon (analogously to the acid effect) induces a photoluminescence quenching. Mn(II) is not able to modify the CNPs, so the carbon dots fluorescence is weakly influenced by the presence of $\mathrm{Mn}$ (II) ions.

\section{Conclusions}

Spent coffee grounds have been successfully used as a carbon source for synthetizing CNPs by an eco-friendly approach working at $200{ }^{\circ} \mathrm{C}$ and at ambient pressure for $90 \mathrm{~min}$ in MilliQ grade water. The complex chemical and mineral composition of coffee grounds, ensuring their peculiar optical properties, have been deeply investigated and exploited for the fast reduction of $\mathrm{Cr}(\mathrm{VI})$ to $\mathrm{Cr}(\mathrm{III})$ in aqueous media in a weak acid environment. The $\mathrm{Cr}(\mathrm{VI})$ remediation process based on the synthetized CNPs has been investigated and clarified by means of spectroscopic approaches. The mechanism has been demonstrated to be ruled by the activation of CNPs surface chemical groups, which became active sites for the chemical reduction of the toxic ion. Further, $\mathrm{Mn}(\mathrm{VI})$ has been reduced to $\mathrm{Mn}(\mathrm{II})$, in water, without acid activation according to data reported in the literature for other carbon based-nanosystems.

Supplementary Materials: The following are available online at https:/ / www.mdpi.com/article/ 10.3390/nano11051064/s1. Figure S1. Up-conversion fluorescence recorded at different excitation wavelengths. Figure S2. $\zeta$-potential performed on the as-synthetized CNPs, after the interaction $\mathrm{KMnO} 4$, after acetic acid ( $1 \mathrm{~h}$ at $\mathrm{pH} 4.5)$ exposure and after acetic acid and dichromate interaction (1 $\mathrm{h}$ at $\mathrm{pH}$ 4.5). Figure S3. (a) Raman spectrum of CNPs after interaction with the chromate/dichromate solution $\left(10^{-4} \mathrm{M}\right)(\mathrm{b})$ Raman spectrum of CNPs after interaction with $\mathrm{KMnO}_{4}$ solution $\left(10^{-4} \mathrm{M}\right)$. Figure S4. FT-IR (in the $1850-800 \mathrm{~cm}^{-1}$ range) spectra of CNPs in presence of Mn(VII) at $\mathrm{pH} 6.6$ (purple line), in presence of $\mathrm{Cr}(\mathrm{VI})$ at $\mathrm{pH} 6.6$ (blue line), treated at $\mathrm{pH} 4.5$ (red line), in the presence of $\mathrm{Cr}(\mathrm{VI})$ at $\mathrm{pH} 4.5$ (green line). Figure S5. Down conversion fluorescence of CNPs at two different $\mathrm{pH}$ values and in presence of $\mathrm{Cr}(\mathrm{VI})$ and $\mathrm{Cr}(\mathrm{III})$. Figure S6. Down conversion fluorescence of CNPs and in presence of potassium permanganate and manganese(II) sulphate.

Author Contributions: Synthesis, UV-Vis and fluorescence spectroscopic and morphological characterizations, R.P. and M.O.; Raman, FT-IR measurements and spectroscopic analysis of remediation process, G.G. and S.B.; XRD, XRF and $\zeta$-potential measurements, S.P. and A.L.; Conceptualization and critical discussion of the synthesis procedure, L.V., S.B and G.G.; Supervision, L.V. and G.G.; Draft writing and Editing, S.B. and G.G. All authors have read and agreed to the published version of the manuscript.

Funding: This research was supported by the PRIN 2017 (protocol number 2017PBXPN4_003), by the INITIO-FET Project (Horizon 2020, Grant Agreement ID: 828779) and by "Research for Innovation" POR PUGLIA FESR-FSE 2014/2020 Ricerca Regione Puglia.

Institutional Review Board Statement: Not applicable.

Informed Consent Statement: Not applicable.

Data Availability Statement: Data is contained within the article.

Conflicts of Interest: The authors declare no conflict of interest.

\section{References}

1. Vishnu, D.; Dhandapani, B.; Kannappan Panchamoorthy, G.; Vo, D.V.N.; Ramakrishnan, S.R. Comparison of surface-engineered superparamagnetic nanosorbents with low-cost adsorbents of cellulose, zeolites and biochar for the removal of organic and inorganic pollutants: A review. Environ. Chem. Lett. 2021, 1, 3. 
2. Gheju, M. Progress in Understanding the Mechanism of CrVI Removal in Fe0-Based Filtration Systems. Water 2018, $10,651$. [CrossRef]

3. Eivazihollagh, A.; Tejera, J.; Svanedal, I.; Edlund, H.; Blanco, A.; Norgren, M. Removal of $\mathrm{Cd}^{2+}, \mathrm{Zn}^{2+}$, and Sr ${ }^{2+}$ by Ion Flotation, Using a Surface-Active Derivative of DTPA (C12-DTPA). Ind. Eng. Chem. Res. 2017, 56, 10605-10614. [CrossRef]

4. Bashir, A.; Malik, L.A.; Ahad, S.; Manzoor, T.; Bhat, M.A.; Dar, G.N.; Pandith, A.H. Removal of heavy metal ions from aqueous system by ion-exchange and biosorption methods. Environ. Chem. Lett. 2019, 17, 729-754. [CrossRef]

5. Henriques, B.; Rocha, L.S.; Lopes, C.B.; Figueira, P.; Duarte, A.C.; Vale, C.; Pardal, M.A.; Pereira, E. A macroalgae-based biotechnology for water remediation: Simultaneous removal of $\mathrm{Cd}, \mathrm{Pb}$ and $\mathrm{Hg}$ by living Ulva lactuca. J. Environ. Manag. 2017, 191, 275-289. [CrossRef]

6. Zhao, F.; Liu, Y.; Hammouda, S.B.; Doshi, B.; Guijarro, N.; Min, X.; Tang, C.J.; Sillanpää, M.; Sivula, K.; Wang, S. MIL-101(Fe)/gC3N4 for enhanced visible-light-driven photocatalysis toward simultaneous reduction of $\mathrm{Cr}(\mathrm{VI})$ and oxidation of bisphenol A in aqueous media. Appl. Catal. B Environ. 2020, 272, 119033. [CrossRef]

7. Peng, D.; Qiao, S.; Luo, Y.; Ma, H.; Zhang, L.; Hou, S.; Wu, B.; Xu, H. Performance of microbial induced carbonate precipitation for immobilizing Cd in water and soil. J. Hazard. Mater. 2020, 400. [CrossRef]

8. Masindi, V. Recovery of drinking water and valuable minerals from acid mine drainage using an integration of magnesite, lime, soda ash, $\mathrm{CO}_{2}$ and reverse osmosis treatment processes. J. Environ. Chem. Eng. 2017, 5, 3136-3142. [CrossRef]

9. Pagano, R.; Quarta, A.; Pal, S.; Licciulli, A.; Valli, L.; Bettini, S. Enhanced Solar-Driven Applications of ZnO@Ag Patchy Nanoparticles. J. Phys. Chem. C 2017, 121, 27199-27206. [CrossRef]

10. Li, M.; Chen, T.; Gooding, J.J.; Liu, J. Review of carbon and graphene quantum dots for sensing. ACS Sens. 2019, 4, 1732-1748. [CrossRef]

11. Chung, S.; Revia, R.A.; Zhang, M. Graphene Quantum Dots and Their Applications in Bioimaging, Biosensing, and Therapy. Adv. Mater. 2019, 1904362. [CrossRef]

12. Sgobba, V.; Giancane, G.; Cannoletta, D.; Operamolla, A.; Hassan Omar, O.; Farinola, G.M.; Guldi, D.M.; Valli, L. Langmuirschaefer films for aligned carbon nanotubes functionalized with a conjugate polymer and photoelectrochemical response enhancement. ACS Appl. Mater. Interfaces 2014, 6, 153-158. [CrossRef]

13. Giancane, G.; Bettini, S.; Valli, L. State of art in the preparation, characterisation and applications of Langmuir-Blodgett films of carbon nanotubes. Colloids Surf. A Physicochem. Eng. Asp. 2010, 354, 81-90. [CrossRef]

14. Zieleniewska, A.; Lodermeyer, F.; Roth, A.; Guldi, D.M. Fullerenes-how 25 years of charge transfer chemistry have shaped our understanding of (interfacial) interactions. Chem. Soc. Rev. 2018, 47, 702-714. [CrossRef]

15. Tao, S.; Zhu, S.; Feng, T.; Xia, C.; Song, Y.; Yang, B. The polymeric characteristics and photoluminescence mechanism in polymer carbon dots: A review. Mater. Today Chem. 2017, 6, 13-25. [CrossRef]

16. Sciortino, A.; Cannizzo, A.; Messina, F. Carbon Nanodots: A Review-From the Current Understanding of the Fundamental Photophysics to the Full Control of the Optical Response. C J. Carbon Res. 2018, 4, 67. [CrossRef]

17. Bettini, S.; Sawalha, S.; Carbone, L.; Giancane, G.; Prato, M.; Valli, L. Carbon nanodot-based heterostructures for improving the charge separation and the photocurrent generation. Nanoscale 2019, 11, 7414-7423. [CrossRef] [PubMed]

18. Testa, C.; Zammataro, A.; Pappalardo, A.; Trusso Sfrazzetto, G. Catalysis with carbon nanoparticles. RSC Adv. 2019, 9, $27659-27664$. [CrossRef]

19. Zhu, S.; Song, Y.; Zhao, X.; Shao, J.; Zhang, J.; Yang, B. The photoluminescence mechanism in carbon dots (graphene quantum dots, carbon nanodots, and polymer dots): Current state and future perspective. Nano Res. 2015, 8, 355-381. [CrossRef]

20. Boakye-Yiadom, K.O.; Kesse, S.; Opoku-Damoah, Y.; Filli, M.S.; Aquib, M.; Joelle, M.M.B.; Farooq, M.A.; Mavlyanova, R.; Raza, F.; Bavi, R.; et al. Carbon dots: Applications in bioimaging and theranostics. Int. J. Pharm. 2019, 564, 308-317. [CrossRef]

21. Benetti, D.; Jokar, E.; Yu, C.H.; Fathi, A.; Zhao, H.; Vomiero, A.; Wei-Guang Diau, E.; Rosei, F. Hole-extraction and photostability enhancement in highly efficient inverted perovskite solar cells through carbon dot-based hybrid material. Nano Energy 2019, 62, 781-790. [CrossRef]

22. Essner, J.B.; Baker, G.A. The emerging roles of carbon dots in solar photovoltaics: A critical review. Environ. Sci. Nano 2017, 4, 1216-1263. [CrossRef]

23. Wu, S.; Zhou, R.; Chen, H.; Zhang, J.; Wu, P. Highly efficient oxygen photosensitization of carbon dots: The role of nitrogen doping. Nanoscale 2020, 12, 5543-5553. [CrossRef] [PubMed]

24. Han, M.; Zhu, S.; Lu, S.; Song, Y.; Feng, T.; Tao, S.; Liu, J.; Yang, B. Recent progress on the photocatalysis of carbon dots: Classification, mechanism and applications. Nano Today 2018, 19, 201-218. [CrossRef]

25. Ibarbia, A.; Sánchez-Abella, L.; Lezama, L.; Grande, H.J.; Ruiz, V. Graphene quantum dot-based hydrogels for photocatalytic degradation of organic dyes. Appl. Surf. Sci. 2020, 527, 146937. [CrossRef]

26. Bayat, A.; Saievar-Iranizad, E. Graphene quantum dots decorated rutile $\mathrm{TiO}_{2}$ nanoflowers for water splitting application. $J$. Energy Chem. 2018, 27, 306-310. [CrossRef]

27. Iqbal, A.; Tian, Y.; Wang, X.; Gong, D.; Guo, Y.; Iqbal, K.; Wang, Z.; Liu, W.; Qin, W. Carbon dots prepared by solid state method via citric acid and 1,10-phenanthroline for selective and sensing detection of $\mathrm{Fe}^{2+}$ and $\mathrm{Fe}^{3+}$. Sensors Actuators, B Chem. 2016, 237, 408-415. [CrossRef]

28. Ji, C.; Zhou, Y.; Leblanc, R.M.; Peng, Z. Recent Developments of Carbon Dots in Biosensing: A Review. ACS Sensors 2020, 5, 2724-2741. [CrossRef] 
29. Yarur, F.; Macairan, J.R.; Naccache, R. Ratiometric detection of heavy metal ions using fluorescent carbon dots. Environ. Sci. Nano 2019, 6, 1121-1130. [CrossRef]

30. Sharma, A.; Das, J. Small molecules derived carbon dots: Synthesis and applications in sensing, catalysis, imaging, and biomedicine. J. Nanobiotechnol. 2019, 17, 92. [CrossRef]

31. Zhi, L.; Müllen, K. A bottom-up approach from molecular nanographenes to unconventional carbon materials. J. Mater. Chem. 2008, 18, 1472-1484. [CrossRef]

32. Sawalha, S.; Silvestri, A.; Criado, A.; Bettini, S.; Prato, M.; Valli, L. Tailoring the sensing abilities of carbon nanodots obtained from olive solid wastes. Carbon N. Y. 2020, 167, 696-708. [CrossRef]

33. Kübel, C.; Eckhardt, K.; Enkelmann, V.; Wegner, G.; Müllen, K. Synthesis and crystal packing of large polycyclic aromatic hydrocarbons: Hexabenzo[bc,ef,hi,kl,no,qr]coronene and dibenzo[fg,ij]phenanthro[9,10,1,2,3- pqrst]pentaphene. J. Mater. Chem. 2000, 10, 879-886. [CrossRef]

34. Đorđević, L.; Arcudi, F.; Prato, M. Preparation, functionalization and characterization of engineered carbon nanodots. Nat. Protoc. 2019, 14, 2931-2953. [CrossRef]

35. Jovanović, S.P.; Syrgiannis, Z.; Budimir, M.D.; Milivojević, D.D.; Jovanovic, D.J.; Pavlović, V.B.; Papan, J.M.; Bartenwerfer, M.; Mojsin, M.M.; Stevanović, M.J.; et al. Graphene quantum dots as singlet oxygen producer or radical quencher-The matter of functionalization with urea/thiourea. Mater. Sci. Eng. C 2020, 109, 110539. [CrossRef]

36. Deng, Y.; Wang, M.; Tian, T.; Lin, S.; Xu, P.; Zhou, L.; Dai, C.; Hao, Q.; Wu, Y.; Zhai, Z.; et al. The effect of hexavalent chromium on the incidence and mortality of human cancers: A meta-analysis based on published epidemiological cohort studies. Front. Oncol. 2019, 9, 24. [CrossRef]

37. Park, S.H.; Alammar, A.; Fulop, Z.; Pulido, B.A.; Nunes, S.P.; Szekely, G. Hydrophobic thin film composite nanofiltration membranes derived solely from sustainable sources. Green Chem. 2021, 23, 1175-1184. [CrossRef]

38. Alammar, A.; Park, S.H.; Ibrahim, I.; Deepak, A.; Holtzl, T.; Dumée, L.F.; Lim, H.N.; Szekely, G. Architecting neonicotinoidscavenging nanocomposite hydrogels for environmental remediation. Appl. Mater. Today 2020, 21, 100878. [CrossRef]

39. Nechyporchuk, O.; Yang Nilsson, T.; Ulmefors, H.; Köhnke, T. Wet Spinning of Chitosan Fibers: Effect of Sodium Dodecyl Sulfate Adsorption and Enhanced Dope Temperature. ACS Appl. Polym. Mater. 2020, 2, 3867-3875. [CrossRef]

40. Rincón-Iglesias, M.; Lizundia, E.; Costa, C.M.; Lanceros-Méndez, S. Tailoring Electrical and Mechanical Properties of All-Natural Polymer Composites for Environmentally Friendlier Electronics. ACS Appl. Polym. Mater. 2020, 2, 1448-1457. [CrossRef]

41. Joe-Wong, C.; Brown, G.E.; Maher, K. Kinetics and Products of Chromium(VI) Reduction by Iron(II/III)-Bearing Clay Minerals. Environ. Sci. Technol. 2017, 51, 9817-9825. [CrossRef] [PubMed]

42. Yan, B.; Chen, Z. Influence of $\mathrm{pH}$ on $\mathrm{Cr}(\mathrm{VI})$ reduction by organic reducing substances from sugarcane molasses. Appl. Water Sci. 2019, 9, 3. [CrossRef]

43. Ahemad, M. Bacterial mechanisms for $\mathrm{Cr}(\mathrm{VI})$ resistance and reduction: An overview and recent advances. Folia Microbiol. 2014, 59, 321-332. [CrossRef]

44. Resta, V.; Calcagnile, L.; Quarta, G.; Maruccio, L.; Cola, A.; Farella, I.; Giancane, G.; Valli, L. Optical and electrical properties of polycarbonate layers implanted by high energy $\mathrm{Cu}$ ions. Nucl. Instrum. Methods Phys. Res. Sect. B Beam Interact. Mater. Atoms 2013, 312, 42-47. [CrossRef]

45. Arumugam, N.; Kim, J. Synthesis of carbon quantum dots from Broccoli and their ability to detect silver ions. Mater. Lett. 2018, 219, 37-40. [CrossRef]

46. Sahu, S.; Behera, B.; Maiti, T.K.; Mohapatra, S. Simple one-step synthesis of highly luminescent carbon dots from orange juice: Application as excellent bio-imaging agents. Chem. Commun. 2012, 48, 8835-8837. [CrossRef]

47. Sharma, A.; Gadly, T.; Gupta, A.; Ballal, A.; Ghosh, S.K.; Kumbhakar, M. Origin of Excitation Dependent Fluorescence in Carbon Nanodots. J. Phys. Chem. Lett. 2016, 7, 3695-3702. [CrossRef]

48. Zhi, B.; Gallagher, M.J.; Frank, B.P.; Lyons, T.Y.; Qiu, T.A.; Da, J.; Mensch, A.C.; Hamers, R.J.; Rosenzweig, Z.; Fairbrother, D.H.; et al. Investigation of phosphorous doping effects on polymeric carbon dots: Fluorescence, photostability, and environmental impact. Carbon N. Y. 2018, 129, 438-449. [CrossRef]

49. Bhaisare, M.L.; Talib, A.; Khan, M.S.; Pandey, S.; Wu, H.F. Synthesis of fluorescent carbon dots via microwave carbonization of citric acid in presence of tetraoctylammonium ion, and their application to cellular bioimaging. Microchim. Acta 2015, 182, 2173-2181. [CrossRef]

50. Bajpai, S.K.; D'Souza, A.; Suhail, B. Blue light-emitting carbon dots (CDs) from a milk protein and their interaction with Spinacia oleracea leaf cells. Int. Nano Lett. 2019, 9, 203-212. [CrossRef]

51. Reis, N.; Franca, A.S.; Oliveira, L.S. Discrimination between roasted coffee, roasted corn and coffee husks by Diffuse Reflectance Infrared Fourier Transform Spectroscopy. LWT Food Sci. Technol. 2013, 50, 715-722. [CrossRef]

52. Figueiró, S.D.; Góes, J.C.; Moreira, R.A.; Sombra, A.S.B. On the physico-chemical and dielectric properties of glutaraldehyde crosslinked galactomannan-collagen films. Carbohydr. Polym. 2004, 56, 313-320. [CrossRef]

53. Ballesteros, L.F.; Teixeira, J.A.; Mussatto, S.I. Chemical, Functional, and Structural Properties of Spent Coffee Grounds and Coffee Silverskin. Food Bioprocess Technol. 2014, 7, 3493-3503. [CrossRef]

54. Chou, W.L.; Wang, C.T.; Huang, K.Y.; Chang, Y.C.; Shu, C.M. Investigation of indium ions removal from aqueous solutions using spent coffee grounds. Int. J. Phys. Sci. 2012, 7. [CrossRef] 
55. Gunasekaran, S.; Sankari, G.; Ponnusamy, S. Vibrational spectral investigation on xanthine and its derivatives-Theophylline, caffeine and theobromine. Spectrochim. Acta Part A Mol. Biomol. Spectrosc. 2005, 61, 117-127. [CrossRef]

56. Silverstein, R.M.; Webster, F.X.; Kiemle, D.J.; Bryce, D.L. Spectrometric Identification of Organic Compounds, 8th ed.; Wiley: Hoboken, NJ, USA, 2014.

57. Zhu, S.; Meng, Q.; Wang, L.; Zhang, J.; Song, Y.; Jin, H.; Zhang, K.; Sun, H.; Wang, H.; Yang, B. Highly Photoluminescent Carbon Dots for Multicolor Patterning, Sensors, and Bioimaging. Angew. Chemie Int. Ed. 2013, 52, 3953-3957. [CrossRef]

58. Sun, L.; Teng, T.H.; Rashid, M.H.; Krysmann, M.; Dallas, P.; Wang, Y.; Hyun, B.R.; Bartnik, A.C.; Malliaras, G.G.; Wise, F.W.; et al. Electrogenerated Chemiluminescence from Carbon Dots. MRS Online Proc. Libr. (OPL) 2010, 1284, 131-136. [CrossRef]

59. Papaioannou, N.; Titirici, M.M.; Sapelkin, A. Investigating the Effect of Reaction Time on Carbon Dot Formation, Structure, and Optical Properties. ACS Omega 2019, 4, 21658-21665. [CrossRef]

60. Kalaiyarasan, G.; Joseph, J.; Kumar, P. Phosphorus-Doped Carbon Quantum Dots as Fluorometric Probes for Iron Detection. ACS Omega 2020, 5, 22278-22288. [CrossRef]

61. Kang, Z.; Lee, S.L. Carbon dots: Advances in nanocarbon applications. Nanoscale 2019, 11, 19214-19224. [CrossRef]

62. Zhang, J.; Zou, H.; Qing, Q.; Yang, Y.; Li, Q.; Liu, Z.; Guo, X.; Du, Z. Effect of chemical oxidation on the structure of single-walled carbon nanotubes. J. Phys. Chem. B 2003, 107, 3712-3718. [CrossRef]

63. Kim, S.; Hee Shin, D.; Oh Kim, C.; Seok Kang, S.; Sin Joo, S.; Choi, S.H.; Won Hwang, S.; Sone, C. Size-dependence of Raman scattering from graphene quantum dots: Interplay between shape and thickness. Appl. Phys. Lett. 2013, 102, 53108. [CrossRef]

64. Kim, S.; Hwang, S.W.; Kim, M.K.; Shin, D.Y.; Shin, D.H.; Kim, C.O.; Yang, S.B.; Park, J.H.; Hwang, E.; Choi, S.H.; et al. Anomalous behaviors of visible luminescence from graphene quantum dots: Interplay between size and shape. ACS Nano 2012, 6, 8203-8208. [CrossRef]

65. Vinci, J.C.; Ferrer, I.M.; Guterry, N.W.; Colón, V.M.; Destino, J.F.; Bright, F.V.; Colón, L.A. Spectroscopic characteristics of carbon dots (C-dots) derived from carbon fibers and conversion to sulfur-bridged C-dots nanosheets. Appl. Spectrosc. 2015, 69, 1082-1090. [CrossRef] [PubMed]

66. Dervishi, E.; Ji, Z.; Htoon, H.; Sykora, M.; Doorn, S.K. Raman spectroscopy of bottom-up synthesized graphene quantum dots: Size and structure dependence. Nanoscale 2019, 11, 16571-16581. [CrossRef] [PubMed] 